\title{
PROTECTING THE LEARNING SPACE: THE CASE FOR THE REGULATION OF STAFF-STUDENT RELATIONSHIPS AT UNIVERSITY CAMPUSES IN SOUTH AFRICA
}

\author{
J. Omar \\ Department of Public Law \\ University of Cape Town \\ Cape Town, South Africa \\ e-mail: jameelah.omar@uct.ac.za
}

\section{ABSTRACT}

Concern over sexual violence at South African higher education institutions has been mounting since 2012. The systemic inquiry into sexual harassment at the University of the Witwatersrand that looked into the patterns, prevalence and problems in regulating sexual harassment at the campus, found that sexual harassment is prevalent and manifests in a number of different ways. In 2016, students at Rhodes University publicised a list of names of alleged sexual offenders at the university (Seddon 2016). The Department of Higher Education and Training has developed a working document, the Draft policy and strategic framework 2017, which seeks to provide a framework for universities and Technical and Vocational Education and Training (TVET) colleges to deal with sexual harassment and sexual offences on campus (Department of Higher Education and Training 2017). It is useful to use the moment of this national debate to highlight the oftenignored issue of sexual relationships between staff and students. This article will consider the merits of regulating these relationships, and how regulation can facilitate mechanisms for accountability and a healthy teaching and learning environment.

Keywords: sexual harassment, consent, higher education

\section{INTRODUCTION}

Concern over sexual violence at South African higher education institutions has been mounting since 2012. The systemic inquiry into sexual harassment at the University of the Witwatersrand that looked into the patterns, prevalence and problems in regulating sexual harassment at the campus, found that sexual harassment is prevalent and manifests in a number of different ways (Mothibi et al. 2013). In 2016, students at Rhodes University publicised a list of names of alleged sexual offenders at the university (Seddon 2016). The pervasiveness of sexual harassment at South African universities has been identified as a significant challenge to women students in higher education (Ministerial Committee on Transformation and Social Cohesion and the Elimination of Discrimination in Public Higher Education Institutions 2008, 117; White Paper on Post-School Education and Training: Department of Higher Education and Training 2013, 1). 
This national trend is in keeping with a global trend that has seen the increase of reported sexual violence cases on university campuses. In January 2014, the White House in the United States of America established a task force to protect students from sexual assault, help improve the safety of American college and university campuses, and to assist American colleges and universities "to meet their obligations" and ensure compliance with federal regulations in this regard (White House Council on Women and Girls 2014).

A number of authors have documented the prevalence of sexual harassment at universities through surveys and other studies (Adams, Mabusela and Dlamini 2013; Joubert, Van Wyk and Rothmann 2011; Dastile 2008; Bennett et al. 2007; Gouws and Kritzinger 2007; Bennett 2002; Mayekiso and Bhana 1997). These studies suggest that sexual harassment in various forms have always formed part of university culture. Some have argued that transformation at universities is increasing the prevalence of sexual harassment (Smit and Du Plessis 2011, 173). In my view, the push for transformation has increased reporting, which is a positive sign that problematic traditions and practices at universities are changing, albeit slowly. As Hooks says:

"[I]n my experiences as a student, it was precisely silence and taboo that made coercion and exploitation more possible .... The moment power differences are articulated ... choice is possible, accountability can be assessed." (Hooks 1995, 38).

With the call for decolonising institutions of higher education, I hope that it will bring with it a greater demand for transparency and accountability.

The Department of Higher Education and Training has developed a working document, the Draft policy and strategic framework 2017, which seeks to provide a framework for universities and Technical and Vocational Education and Training (TVET) colleges to deal with sexual harassment and sexual offences on campus (Department of Higher Education and Training 2017). With the issue now finally on the national agenda, along with the increased pressure on South African institutions to transform and to address "rape culture", it is worth (re)considering the role of the university in ensuring a safe and conducive learning and work environment for students and staff members.

This article will focus on the discrete issue of romantic or sexual relationships between staff and students at universities, for ease of reference, referred to herein as "sexual relationships". These relationships are not discussed in the Draft policy and strategic framework produced by the Department of Higher Education. I will argue that these relationships must be carefully regulated as part of a university's holistic approach to sexual harassment and the prevention of sexual violence on university campuses. This is because the power imbalance 
between staff and students is one that is inherent to the characterization of sexual harassment (this discussion is elaborated on under the heading "Why are staff-student relationships part of the sexual harassment debate?" below). The arguments made will be structured as follows: The next section will discuss what is meant by a sexual relationship between a staff member and student for the purposes of the proposed policy and the nature of a teacher-student relationship. After that the potential harms that can arise as a result of staff-student sexual relationships will be discussed. Then the arguments for and against the regulating of staff-student sexual relationships will be considered. The substantive content of a policy that regulates sexual relationships will be proposed in the section before the Conclusion.

The policy I argue for is a consensual sexual relationships policy between staff and students. Ultimately, the argument is that there ought to be regulation of sexual relationships between staff and students. An outright prohibition would deny the opportunity to provide counselling, keep records of staff-student relationships and put measures in place to ensure that the environment of learning is safeguarded. These issues will be elaborated on throughout the article. The next part reflects on the nature of staff-student relationships and the particular problems that ensue when the staff member is a member of the teaching staff.

\section{THE NATURE OF STAFF-STUDENT RELATIONSHIPS}

There are a number of personal relationships that could occur in the university context between staff and students. Staff members may have family members who become students - their own children, nieces and nephews, spouses. Friends or family friends could become students. Relationships can also develop during the staff-student period of interaction. Staff and students form friendships and strong work bonds that go beyond the more distant staff-student relationship. A romantic or sexual relationship may pre-exist entry into the university, such as between spouses. Even though this involves a sexual relationship, it is easier to manage because the relationship does not emanate from the staff-student relationship.

All of the above types of relationships are, for the most part, relatively easy to regulate because it is clear that the primary harm is potential bias (in most of these examples it is likely to be a positive bias) or the perception of bias. It may be sufficient to ensure that a staff member who has a prior or present familial or friendly relationship with a student is not permitted to directly supervise or assess that student's work. This would be relatively uncontroversial. In the same way that a judge or magistrate should recuse themselves from presiding over a matter that involves a friend or family member, the same rationale exists for eliminating the perception of bias in the learning environment.

The crux of the ongoing debate is relationships between staff and students that are 
romantic or sexual in nature and that exist during the course of the staff-student relationship. It is not a requirement that the relationship develop during the course of a direct supervisory or assessment relationship. It may be problematic even in an indirect supervisory relationship, such as with a lecturer who will teach that student at a later stage in the degree.

There may also be a difference between how staff-student relationships are regulated when the staff member is an academic member or administrator, or when the student is an undergraduate or postgraduate student. The latter distinction relates primarily to the age of the student and an assumption of maturity. I take the view that there should be little if any distinction between undergraduate and postgraduate students with respect to regulating sexual relationships with staff members, because the rationale of policies regulating such relationships (discussed further under the heading "Rationale for treating staff-student sexual relationships with caution") is equally applicable to all students. In terms of the standing of the staff member, the most obviously problematic sexual relationships are those entered into by an academic staff member who has a direct academic relationship with a student. But there are other staff members who may equally have a significant impact on a student's academic life, for example, a staff member who works in the residence where the student resides, or an administrative assistant in the department where the student is registered.

It could be argued that sexual relationships at a university campus should be strictly regulated regardless of the role that the staff member plays in relation to the student because the impact on the student may be similar due to age, position and gender. In other words, the same restrictions should apply regardless of whether the scenario involves a staff member contracted to work in IT support, who has no direct contact with students, or a professor who is responsible for lecturing and marking the assignments of students. I argue below that the same requirements of disclosure should apply regardless of the designation of the staff member, however, the measures put in place to mitigate harm may be different based on the role of the staff member.

There is an inherent power imbalance in a relationship between a staff member and a student. Because of the power imbalance, when a professional relationship is combined with a personal one, it can lead to breaches of trust and conflicts of interest (Forell 1997, 54). Such a break in trust can arise in respect of the individual student in question but also the broader group of students who may suspect bias.

Notwithstanding the equally harsh impact that could arise from a relationship between any staff member and a student, there is a particularly significant impact where the staff member is a member of the academic staff. The relationship between a teacher and student has to involve trust and respect in order to facilitate learning. Some authors have described the relationship as 
a "fiduciary relationship", where the teacher has a duty of care towards a student (Forell 1997, 55). The teacher's role in loco parentis may not be applicable in higher education between students and lecturers, because, most obviously, university students are over the age of eighteen and therefore legally adults with the capacity to regulate their own affairs.

Regardless of whether individual lecturers have a fiduciary duty towards students, the university has a fiduciary duty to protect students from harm on its premises and from persons in its employ. The university equally has the duty to protect the work environment for its staff members in compliance with its obligations under the Employment Equity Act 55 of 1998. This duty of care creates the impetus to clarify rules regarding personal relationships among members of the university community.

\section{RATIONALE FOR TREATING STAFF-STUDENT SEXUAL RELATIONSHIPS WITH CAUTION}

Although the university encompasses a geographic space, it is the space of learning that these policies are aimed at protecting. The university goes far beyond the lecture halls or the direct academic roles of a lecturer and student. Instead, a university is an intangible intellectual hub. University is a place of transition, where students begin the move from adolescence into adulthood. For the purposes of the law a person is an adult at eighteen, but for the most part undergraduate students are and some will continue to be impressionable. While this does not mean that they do not have the capacity to consent to a sexual relationship, it does mean that they are potentially vulnerable to sexual propositions, including - or perhaps even especially from their teachers. A good university lecturer embraces the task of challenging students, making them question boundaries and broadening their minds. This places the student in a disturbing and new environment, one where a relationship of trust with their teacher is essential to learning. A sexual relationship, even where it is consensual can change the substance of the student's relationship with the lecturer so that trust and respect between the parties is strained (Mack 1999, 80). Such a break in the relationship between a lecturer and student can have farreaching negative effects on a student's emotional and intellectual stability. These harms are expanded upon further in the next section.

\section{What is the harm involved in staff-student relationships?}

The most fundamental harm for an academic institution is that a staff-student sexual relationship may interfere with the learning environment. The student engaged in the relationship may suffer academic harm, particularly where the relationship breaks down. Such a student may miss classes, change courses, or even drop out of university. A student may give 
up their academic aspirations or remain in a role of a research assistant longer than the norm (Sanger 1998, 1873-1874). The ability of the lecturer to fairly assess that student's work will be compromised, as they may subconsciously treat that student more favourably. The reverse could also happen where the lecturer marks more harshly to avoid a challenge of bias.

If word gets out about the student's relationship with the faculty member, the student may suffer the moral disapproval of the other students and faculty members (Forell 1997, 59). The student may be subjected to the hostility of classmates and be socially alienated. There is also harm to other students en masse, since they will perceive (whether accurately or not) that the student engaged in the relationship is receiving beneficial treatment. This breaks the pedagogical relationship between the lecturer and all students. Some students may also be wary of the particular staff member, and fear being a romantic target.

There is also a clear risk of harm to the staff member involved in a sexual relationship with the student. They could later be subjected to a sexual harassment charge, which is embarrassing and career damaging. The member of staff may also face moral disapproval from colleagues and students. These perceptions could have far-reaching career implications, such as affecting promotion cycles, management positions, and references should the staff member wish to change jobs. It is worth noting the converse. Notwithstanding the professional reputational risk, staff members may also garner admiration at a social level, especially where they are older and the student is young. The student too may be perceived as sophisticated and mature for conducting a relationship with an older person, especially where it is an academic.

The university may suffer potential harm. The institution has a responsibility to protect students from potentially harmful conduct by its employees (Forell 1997, 61) and may receive negative publicity, which would affect enrolments, hiring and government subsidies. Hill and Silva highlight the risks for students that result from sexual harassment:

"For colleges and universities, sexual harassment can be costly and damage their reputations, but the emotional and academic wellbeing of students should be the highest priority. Sexual harassment can damage students' wellbeing, provoke and exacerbate conflict among students, and contribute to a hostile learning environment." $(2005,2-3)$

It is therefore arguable that even though the university should be conscious of its reputational damage, its fiduciary duty to students provides sufficient impetus to deal appropriately with staff-student relationships. Finally, there is also the broader rationale of changing perceptions, beliefs and the culture at universities that have historically permitted relationships between academic staff and students. The harsh critique against universities is that the acceptance of such relationships perpetuates rape culture. 


\title{
Why are staff-student relationships part of the sexual harassment debate?
}

Catharine MacKinnon first highlighted sexual harassment for women in the workplace and brought it to popular attention (MacKinnon 1979). Sexual harassment is defined in South Africa's Code of Good Practice on the Handling of Sexual Harassment as:

\begin{abstract}
"unwelcome sexual advances, requests for sexual favours, verbal or physical conduct of a sexual nature, including instances where such favours or conduct are implicitly or explicitly made a condition of employment, continued employment or promotion." (National Economic Development and Labour Council 1998).
\end{abstract}

The Code aims to eliminate sexual harassment in the workplace (in a broad sense) and encourages and requires appropriate procedures to deal with sexual harassment. Sexual harassment is also argued to form part of embedded rape culture, which is defined as:

\begin{abstract}
"A complex set of beliefs that encourage male aggression and supports violence against women. It is a society where violence is seen as sexy and sexuality as violent. In a rape culture, women perceive a continuum of threatened violence that ranges from sexual remarks to sexual touching to rape itself. A rape culture condones physical and emotional terrorism against women as the norm. In a rape culture both men and women assume that sexual violence is a fact of life itself, inevitable." (Buchwald, Fletcher and Roth 2005, 1).
\end{abstract}

This definition articulates the embedded gender power imbalance that underpins feminist theory (Hooks 1984, 26). Hierarchies within the institution create another category of power imbalance. In South African universities, some more than others, these hierarchies still reflect a gendered demographic, where men remain the majority and generally more senior in the institution (Van Wyk 2014). Junior members of the community, which could be staff or students, are "vulnerable to unwanted sexualisation from senior men" (Bennet et al. 2007, 88) because of the power imbalance. Sexual harassment is a means to perpetuate "the gendered status quo" (Robinson 2000, 82 where, particularly, male dominance over women is the norm. Along the spectrum of sexual activity that ranges from mutual and consensual sexual relations to sexual violence, lies the issue of romantic or sexual relationships between staff and students. It too is a murky area, where the lines of power and consent become ever more blurred.

Sexual harassment in South African law is seen as an injury to a person's dignity and a form of unfair discrimination (Snyman-Van Deventer and De Bruin 2002, 196). Sexual harassment policies are specifically focused on harassment that is actionable. In some cases, the sexual harassment claim could even fall within the scope of a criminal offence in terms of the Criminal Law (Sexual Offences and Related Matters) Act 32 of 2007 (hereafter SORMA). 
This focus on actionable sexual harassment claims, while appropriate for a sexual harassment policy, creates a gap that leaves the university unable to intervene before the sexual conduct becomes a serious issue. It also leaves students in a vulnerable position, denying them the opportunity of accessing support and resources, such as counselling, health care and legal support. A student may be unsure whether they are comfortable with the relationship. It is possible that they are unsure of the level of coercion involved, as a relationship between a staff member and student may include degrees of both consent and coercion. They may want a safe and confidential avenue for advice that could include advice on whether to lay a complaint of sexual harassment.

A number of South African universities have sexual harassment policies, including, the University of Cape Town (UCT), the University of the Western Cape, Stellenbosch University, University of Johannesburg, the University of the Witwatersrand (Wits), Rhodes University, Nelson Mandela Metropolitan University (NMMU), the University of Kwazulu-Natal (UKZN) and the University of South Africa (UNISA). In 2015, the student representative council at Walter Sisulu University advocated for the creation of policies aimed at sexual harassment (Cezula 2015). If such a policy has been drafted, I was not able to locate it. Many TVET colleges do not have policies in place (Department of Higher Education and Training 2017, 5). Of the universities that have sexual harassment policies, only a few appear to have policies that deal specifically with relationships between staff and students. Those that do have such polices include UCT, Wits and Rhodes. There may be other universities that have similar policies, but I was not able to locate them.

Many of the websites of these universities are confusing and requires some investigation to locate the relevant policy on sexual harassment or relationships between staff and students. For example, UCT's policy on sexual harassment is easily located on its human resources website, but its "special relationships policy" is not listed there. According to a reference in UKZN's sexual harassment policy, a policy on managing conflicts of interest between staff and students exists, but this policy could not be found on the website. UNISA lists sexual harassment as a transgression of its policy on academic integrity. The policy states that different transgressions are dealt with differently according to its level of seriousness. There is no clarity provided on the category of seriousness accorded to sexual harassment complaints, nor who makes such a determination. The difficulty with which these policies can be located feeds into the failure to deal effectively with sexual harassment (Joubert, Van Wyk and Rothmann 2011, $6)$.

Policies that exist in various universities have been criticized for not adequately dealing with sexual harassment on campus, such as through the Rhodes University protests. University 
campuses are microcosms of society, and the prevalence of violence against women remains a national issue of concern in South Africa (Wilkinson 2016).

I argue that staff-student sexual relationships and sexual harassment are two aspects of the same impetus towards the eradication of rape culture at universities. However, preventing sexual harassment cannot be the only justification for the regulation of staff-student sexual relationships (Jafar 2003, 46). While recognising their inter-relationship, they need to be individually regulated, acknowledging the objectives of the two policies as being significantly different. Nonetheless, because a consensual sexual relationships policy would create the space for counselling, health care and other support, it may have some impact on preventing sexual harassment through its empowerment of students.

\section{REGULATING STAFF-STUDENT SEXUAL RELATIONSHIPS}

Regulation does not have to mean prohibition. Regulations set the rules for permissible conduct, for processes to deal with conflict and for mechanisms of accountability. In other words, regulating something can mean ensuring that the conduct, should it occur, does so according to an agreed set of rules.

A consensual sexual relationships policy between staff and students can permit such relationships subject to certain conditions. Recommendations for these conditions will be discussed under the heading "Regulating staff-student sexual relationships" below. The overall rationale of a consensual sexual relationships policy is to promote an effective learning environment for students (Mack 1999, 84). There are two sub-purposes of regulating consensual relationships between staff and students. The first is that the academic relationship needs to be safeguarded in order to protect the integrity of the assessment process, and to protect the intellectual and emotional development of students. The second is that the culture at universities, a culture that reflects a societal norm, needs to transform to prevent the acceptance of sexual harassment and rape culture generally from continuing. This has been discussed above under the heading "Why are staff-student relationships part of the sexual harassment debate?", and therefore the focus of the next sub-section will be on the academic environment.

\section{What would a policy do?}

A consensual sexual relationships policy is aimed at situations that do not amount to sexual harassment (Mack 1999, 82) and aims to promote an effective environment of learning for students (Mack 1999, 79) and a productive working environment for staff. The Code of Good Practice on Handling Sexual Harassment Cases states as one of its guiding principles as discussed below under the heading "Drafting a consensual sexual relationships policy" that 
"employers should create and maintain a working environment in which the dignity of employees is respected". The risk of harm to various involved parties (discussed above under the heading "What is the harm involved in staff-student relationships?") can be mitigated if a university has a good consensual relationships policy. First, it discourages staff from engaging in sexual relations with a student by articulating the risks and alerting staff members to possible sanctions. Secondly, if a university adopts a consensual relationships policy, the policy can be drafted to include procedures that ought to be followed to ensure that a student can report such a relationship in confidence and seek advice as to whether there are grounds for a claim of sexual harassment (Mack 1999, 84). Even where a student is a willing participant in the relationship, they may still feel uncomfortable about it. Mechanisms can be put in place to allow the student a safe space in which to seek advice. With a policy in place students can be made more aware of the harms to themselves if they engage in sexual relations with their lecturers. Students need to be made aware of the risks in order to make responsible decisions and protect themselves from these harms.

A consensual relationships policy can assist the university in dealing with situations where there was initially consent in the relationship but it was thereafter withdrawn. A consensual relationship policy can assist in preventing allegations of sexual harassment that do not clearly fall within its scope (Young 1996, 6). In a situation where a student no longer feels comfortable in a relationship with their teacher, the student can seek advice about how to end the relationship without being obliged to lay a complaint of sexual harassment. In the absence of regulation, students are denied this avenue of counselling and support, and are caught between laying a formal sexual harassment complaint or staying silent. If relationships between staff and students were understood more fully, and were understood as issues that are interrelated, universities would be able to develop better advocacy and educational campaigns that seek to prevent harassment in all forms.

The university mitigates its own potential liability by adopting a policy that regulates staffstudent relationships. Universities have a legitimate interest in eliminating the possibility of coercion (whether intended or not), favouritism, or the appearance of bias, that has the potential to affect the academic integrity of the institution. Because of its fiduciary obligation, the university has the responsibility to ensure that students are protected from people in its employ, particularly where those people are in charge of a student's intellectual and academic development.

\section{Arguments against regulation}

There are various arguments that have been levelled against the regulation of consensual sexual 
relationships at universities. Many of these arguments are relevant and useful critiques that can be used to tailor a workable policy. There are three arguments that I will consider: that the conduct is not criminal, that consent has been given, and that regulation infringes the right to privacy.

\section{The conduct is not criminal}

The primary basis for disputing the legitimacy of consensual relationship policies is that these relationships are not unlawful in terms of the sexual offences laws in South Africa. Neither SORMA nor the legal framework for higher education regulates relationships between staff and students. Objections are thus raised against the interference by universities (Elliott 1999-2000, 50). However, universities are academic institutions that are permitted to establish their own community standards. Such standards cannot conflict with the law of the state, but can regulate beyond what is criminal. An example is a company regulating the use of social media. The state would only interfere with the use of social media where its use meets the definition of a crime. However, a company is permitted to limit the use of social media on its premises, with the use of its facilities and to protect against reputational damage. Conduct could breach the law and simultaneously the standards set by a university. An example of this is sexual harassment. It is also possible that conduct that does not infringe criminal law may breach university standards. Universities can thus set standards and conditions to which all members of the community must abide.

\section{Consent}

Consent, as is often the case in sexual matters, is a question that arises both for those advocating for and those arguing against sexual relationship policies (Elliott 1999, 53-54; DeChiara 19871988, 141-142; Mack 1999, 92-93). As already mentioned, critics of consensual sexual relationship policies argue that students are adults and are capable of and frequently do consent to relationships with staff members (Elliott 1999, 53-54). The caricatured image of a staffstudent relationship is one of a lecherous professor, probably old and male, who preys on a young and vulnerable female student. From various cases that have been reviewed at South African universities, this caricature is oftentimes not far from the truth (Zwane 2013). But these are not the exclusive typography of staff-student relationships. What happens in a situation where it is the student who makes the first sexual advance or initiates the relationship? This does not deviate from the point that students need to be protected. A good relationships policy should go further than prohibiting sexual relationships between staff and students and should create mechanisms to support students with advice and counselling opportunities. 
The counter-argument is whether consent can be genuine and informed on the part of the student, given the unequal power balance inherent in the lecturer-student relationship. The unequal position in which students find themselves arise from various factors, such as age, gender, the position of the staff member, and the extent to which that position allows the lecturer to affect the student's academic performance. These factors affect whether consent is meaningful (Mack 1999, 94). This scenario is analogous to the offence of grooming enshrined in chapter 11 of SORMA. Grooming is explained as:

\begin{abstract}
"Sex offenders target children and develop a relationship with them in order to gain sexual access to the child. At its most basic, this is referred to as the 'grooming' process. The grooming process provides the tools for manipulation through the offering of gifts, fulfilling the child's basic need for attention, praise, affection and closeness, and reworking these needs into an inappropriate sexual relationship. This manipulation of the child is viewed as the first step on the path to sexual abuse, which is why it is criminalised ...." (Pithey and Muller 2014, ch11 p1).
\end{abstract}

Like with grooming, there may be staff members that repeatedly engage in sexual relationships with students. Such a staff member may effectively prey on vulnerable students.

A sexual relationships policy should deal specifically with the scenario of a staff member who is consistently involved in sequential relationships with different students. While these relationships may appear consensual, it is the university's responsibility to ensure that students are protected from staff members who consistently target new students.

Young has described sexual contact between a professor and student as falling along a continuum of exploitation, which she calls "power dependency" (Young 1996, 7). Consent can therefore be misleading, and ought not to be relied upon to argue that there should be no policy at all regulating sexual relationships between staff and students. It could be argued that every relationship contains an element of power imbalance, whether age, gender or economic strength (Young 1996, 2). While this may be true, other relationships can be distinguished from the teacher-student relationship. For one thing, when a faculty member and a student are involved in a sexual relationship, there is potential harm to third parties as well as the primary parties. A policy can address these further risks and make sure that the perceived bias of the lecturer will not compromise the pedagogical relationship which lies at the heart of the lecturer-student relationship. More importantly, unlike other relationships where the power differential stems from factors such as age or class, in the faculty-student scenario the power differential is inherent in the fact that the lecturer is in a position of power as teacher.

The issue ought not to be focused on whether students are capable of consenting, but rather on whether the university has a legitimate interest in and duty to regulate these relationships. While it is true that university students are adults, it does not follow that adult behaviour should 
not be regulated. There are everyday examples of regulation of legal activities, such as traffic laws. Consent is therefore a peripheral issue that need not have a bearing on the existence of a regulatory policy, only on how a university chooses to regulate.

Since I am not proposing a complete ban on faculty-student relationships, it seems to me to be justified for a university to adopt a policy that protects its students, while still respecting and maintaining the individual freedoms of students and staff alike.

\section{The right to privacy}

Privacy is a right enshrined in section 14 of the Constitution of the Republic of South Africa, 1996. But privacy ought not to be oversimplified. The rights in the Bill of Rights require the balance of competing rights (Woolman and Chaskalson 2009, 51-165). Any infringement of a right must meet the test for limitation in section 36. Elliott argues that consensual sexual behaviour is not the business of any governing body (1999-2000, 69). Although a section 36 limitations analysis will not be undertaken here, in my view the harms already discussed above serve as adequate justification for a slight limitation of the right to privacy.

Matters that are relegated to the private often create immense problems for vulnerable groups (Forell 1997, 68). A good example of this is domestic violence. In the recent past, this was treated as an issue between a husband and wife - a private one. Today we realise that privacy cannot override the harm that is inflicted on individuals (although the silence and stigma of the issue remains a problem).

It is proposed that the obligation to disclose be included in sexual relationship policies. Such a disclosure requirement may be challenged for its infringement of the right to privacy, but this can be managed. Disclosure should be to a designated office. The information is not made public. The rationale for obligating the member of staff to disclose a sexual relationship is three-fold: First, it ensures that arrangements will be made to remove the staff member from involvement in that particular student's academic assessment, whether marking tests or assignments or supervising research. Secondly, it can provide a test for whether there is real consent or not. Before disclosing such a relationship to a superior, the staff member concerned would have to ensure that the student is willing to have the relationship disclosed to the university. The lecturer themselves would also be forced to think carefully about the nature and seriousness of the relationship before disclosing. Thirdly, it protects the university from future claims of failing to deal with sexual harassment, as it provides an opportunity for intervention where it is suspected that the relationship is a harmful one. 


\section{DRAFTING A CONSENSUAL SEXUAL RELATIONSHIPS POLICY}

Elliott criticises sexual relationships policies for being "hastily drafted, resulting in imprecise language, vague terms with conflicting interpretations, and confusion over exactly what was being proscribed" (Elliott 1999-2000, 48). Unfortunately, this criticism tends to be true. Insufficient thought has been given to how to draft these policies and what they are aimed at achieving. This section sets out a framework for content to be included in such a policy.

There are two broad types of sexual relationship policies. The first are those that prohibit staff-student relationships completely, regardless of the role of the staff member and their positioning to the student. Critics argue that such a policy does not put a stop to these relationships (Hooks 1995, 37-38). At most, it becomes a better-kept secret, which may relegate students to an even greater level of vulnerability. It may also discourage students from reporting inappropriate behaviour from a staff member for fear of themselves receiving censure for breaching the policy.

Then there are policies that discourage relationships between staff and students but do not expressly prohibit them. I argue that this is a useful approach to adopt. It acknowledges that in a university setting, because of the power differential, relationships between staff and students are generally not a good idea. Such a policy is aimed at preventing interference with the learning environment and will ensure that where there is a direct academic relationship between the staff member and student, measures are put in place to remove assessment or supervision from the staff member's ambit. This policy would be limited if it focused only on academic roles and did not include the broader considerations of rape culture in its ambit. Thus, the policy must deal with situations involving academic and non-academic staff and have a holistic approach to the impact on the student. The measures that are put in place could be less stringent where the staff member is not a member of the academic staff or is in a different faculty.

It is necessary in any policy to be specific about how staff members of different designations are regulated. Sexual relationships with students can be discouraged for all staff members. But where the staff member is an academic member the reporting lines may be different. For example, an academic member may have to disclose to the dean of their faculty instead of their line manager. This may be different for non-academic staff. Arguably, all staff should also have to report to a central office, such as the office that deals with sexual harassment claims. The consequences after disclosure may also be different based on who the staff member is. An administrator in a student housing department involved in a relationship with a student who does not live in residence and has no reason to engage with the student housing department may require no further measures than recordal of the relationship and the offer of support to the student. On the other hand, if a humanities student is in a relationship with a professor in the 
philosophy department, measures would have to be taken to ensure that the staff member has no oversight over the student's academic affairs. This would need to be regularly monitored as the student progresses. Where the student changes programmes or chooses electives, the dean would have to ensure that strict non-involvement continues.

It is logical and rational to enforce a stricter policy with regard to academic staff because of the direct impact on the student's academic performance and development. Any relationship between a staff member and student that ends badly would potentially create a hostile campus environment for the student. Perhaps this is true of any relationship for the student, not only ones with staff members, but the purpose of these policies is not to protect students from heartbreak, but to mitigate the impact on their academic life.

Procedures must be clearly spelt out in the policy, both the procedures for disclosure and also the procedure for grievances. It must be clarified how the policy can be breached, specifically whether there is a stand-alone sanction for non-disclosure. The risks that potentially accrue in a staff-student relationship have to be clear to the staff member and the student in order to ensure that an informed decision has been taken by both parties. A holistic process must be included that offers counselling, advice, health services, and other support to the student.

To make good on the argument that disclosure will not unjustifiably or excessively infringe the right to privacy, disclosure should also be made to an objective body, situated outside the faculty. In my view, this should be a central office, perhaps the one that handles sexual harassment cases. This will allow for consistency of approach, ensure that there are persons trained to implement the policy, offer support, and trigger the mechanisms for protection. It is important to have an objective body that handles and oversees these situations. A line manager (included here is heads of department, deans, heads of school or administrative heads) should not have to deal with these issues, especially in the absence of proper training. Fairness requires that the policy be implemented uniformly across the university. It is important that there is one primary reporting office, as multiple avenues for compliant has continually been criticised in available research (Bennett et al. 2007, 88; Mothibi et al. 2013, 35).

It would be necessary that the line manager is made aware of the relationship where appropriate, especially where the staff member and student are in the same faculty or department. The dean or head of department may have to ensure marking and supervision is reallocated. If it is the dean who is in a relationship with a student, the line manager of the dean (probably a deputy vice-chancellor) must be informed. Oversight remains with the central office, whose role is oversight of possible disciplinary proceedings, accountability and consistency of the process. Any policy has to be drafted in general terms to make it applicable for a wide range of conduct. 


\section{CONCLUSION}

This article has focused on the need for a consensual sexual relationships policy between staff and students at universities. These policies are needed to prevent the normalisation of sexual relations between staff and students, especially academic staff because of the inherent power imbalance and the impact on the learning space. This is part of the rape culture debate that has challenged a number of South African universities in the past few years.

Fundamentally, these policies are aimed at protecting the academic and learning space of a university. The often fine line between real consent and coercion makes it even more essential that the university takes responsibility for ensuring that students who participate in relationships with staff members understand the risks involved and accept them voluntarily. This approach recognises that the academic space fails to thrive where there is an environment of hostility and fear.

The type of policy that is argued for is one that looks beyond a disciplinary process, and includes mechanisms for support, such as, counselling, health care and legal advice, where appropriate. If a sexual relationships policy is integrated into the university discourse as part of the prevalent problem of sexual harassment, the university would be able to create more widespread advocacy and education campaigns that target the prevention of harassment.

With the publicity raised about this issue in various reviews and in the media generally, it is no longer possible to sweep it under the carpet. University is a place of intellectual stimulation, not sexual stimulation. These policies are legitimate and necessary in ensuring equal access to a campus environment that is conducive to learning.

\section{REFERENCES}

Adams, J. D., M. S. Mabusela and E. T. Dlamini. 2013. Sexual harassment: The 'silent killer' of female students at the University of Ayoba in South Africa. South African Journal of Higher Education 27(5): 1149-1163.

Bennett, Jane, Amanda Gouws, Andrietta Kritzinger, Mary Hames and Chris Tidimane. 2007. 'Gender is over': Researching the implementation of sexual harassment policies in Southern African Higher Education. Feminist Africa 8: 83-104.

Bennett, Jane. 2002. Sexual violence/harassment: A handbook of resources. Cape Town: African Gender Institute, University of Cape Town.

Buchwald, Emilie, Pamela R. Fletcher and Martha Roth. 2005. Transforming a rape culture. Minneapolis, MN: Milkweed Editions.

Cezula, Thando. 2015. SRC to tackle sexual harassment. Walter Sisulu University Daily News, September 28, 2015. http://www.wsu.ac.za/waltersisulu/index.php/src-to-tackle-sexualharassment/

Constitution of the Republic of South Africa 108 of 1996.

Criminal Law (Sexual Offences and Related Matters) Act 32 of 2007. 
Dastile, Nontyatyambo Pearl. 2008. Sexual victimisation of female students at a South African tertiary institution: The victim's perception of the perpetrator. Acta Criminologica 2: 189-206.

DeChiara, Peter. 1987-1988. The need for universities to have rules on consensual sexual relationships between faculty members and students. Columbia Journal of Law and Social Problems 21: 137162.

Department of Higher Education and Training. 2017. Addressing gender-based violence in the postschool education and training sector: draft policy and strategic framework. Pretoria: Department of Higher Education and Training.

Department of Higher Education and Training. 2013. White Paper on Post-School Education and Training. Pretoria: Department of Higher Education and Training.

Elliott, Gary. 1999-2000. Consensual relationships and the constitution: A case of liberty denied. Michigan Journal of Gender and Law 6: 47-77.

Employment Equity Act 55 of 1998.

Forell, Caroline. 1997. What's wrong with faculty-student sex? The law school context. Journal of Legal Education 47(1): 47-72.

Gouws, Amanda and Adrienetta Kritzinger. 2007. Dealing with sexual harassment at institutions of higher learning: Policy implementation at a South African university. South African Journal of Higher Education 21(1): 68-84.

Hill, Catherine and Elena Silva. 2005. Drawing the line: Sexual harassment on campus. Washington: American Association of University Women Educational Foundation.

Hooks, Bell. 1984. Feminist theory: From margin to center. Boston: South End Press.

Hooks, Bell. 1995. In praise of student/teacher romances: Notes on the subversive power of passion. Utne Reader (March-April): 36-37.

Jafar, Afshan. 2003. Consent or coercion? Sexual relationships between college faculty and students. Gender Issues 21(1): 43-58.

Joubert, Pierre, Christo van Wyk and Sebastiaan Rothmann. 2011. The effectiveness of sexual harassment policies and procedures at higher education institutions in South Africa. SA Journal of Human Resource Management 9(1): 1-10.

Mack, Margaret H. 1999. Regulating sexual relationship between faculty and students. Michigan Journal of Gender and Law 6(1): 79-112.

MacKinnon, Catharine. 1979. Sexual harassment of working women: A case of sex discrimination. New Haven: Yale University Press.

Mayekiso, T. V. and K. Bhana. 1997. Sexual harassment: Perceptions and experiences of students at the University of Transkei. South African Journal of Psychology 27(4): 230-235.

Ministerial Committee on Transformation and Social Cohesion and the Elimination of Discrimination in Public Higher Education Institutions. 2008. Transformation and Social Cohesion and the Elimination of Discrimination in Public Higher Education Institutions. 2008. Pretoria: Department of Education. https://www.ukzn.ac.za/wp-content/miscFiles/publications/Reporton HE andTransformation.pdf

Mothibi, Joe, Veruschka Naicker, Bonita Meyersfeld and Jameelah Omar. 2013. Independent inquiry into allegations of sexual harassment at the University of the Witwatersrand, Johannesburg. https://www.wits.ac.za/media/wits-university/faculties-and-schools/commerce-law-andmanagement/research-entities/cals/documents/programmes/gender/Final\%20Report\%20 Independent $\% 20$ Inquiry\%20into $\% 20$ Sexual $\% 20$ Harassment $\% 20$ at $\% 20 \mathrm{Wits} \% 20$ University $\%$ 203\%20September\%202013.pdf

National Economic Development and Labour Council. 1998. Code of Good Practice on the Handling of Sexual Harassment.

Nelson Mandela Metropolitan University. Gender equity policy. http://tme.mandela.ac.za/PoliciesOther-Important-Documents 
Pithey, Bronwyn and Karen Muller. 2014. Sexual grooming of children. In Sexual offences commentary, ed. Dee Smythe and Bronwyn Pithey. Chapter 11. Cape Town: Juta.

Rhodes University. Protocol on managing of close relationships between staff and students and between staff. https://www.ru.ac.za/media/rhodesuniversity/content/humanresources/documents/ protocols/Protocol\%20on\%20Managing\%20Close\%20Relationships\%202012\%20(2).doc

Rhodes University. Sexual assault protocol. https:/www.ru.ac.za/media/rhodesuniversity/content/ institutionalplanning/documents/Protocol\%20on\%20Sexual\%20Assault.pdf

Robinson, K. 2000. 'Great Tits, Miss!' The silencing of male students' sexual harassment of female teachers in secondary schools: A focus on gendered authority discourse. Studies in Cultural Politics of Education 21(1): 75-90.

Sanger, Carol. 1998. The erotics of torts. Michigan Law Review 96: 1852-1883.

Seddon, Deborah. 2016. "We will not be silenced": Rape Culture, \#RUReferencelist, and the University Currently Known as Rhodes. Daily Maverick, June 1, 2016. https://www.dailymaverick. co.za/opinionista/2016-06-01-we-will-not-be-silenced-rape-culture-rureferencelist-and-theuniversity-currently-known-as-rhodes/\#.Wlyxxa6WaUl

Smit, Denine and Voet du Plessis. 2011. Sexual harassment in the education sector. Potchefstroom Electronic Law Journal 14: 172-217.

Snyman-Van Deventer, Elisabeth and Jaco de Bruin. 2002. Sexual harassment in South African and American law. Acta Academica Supplementum 2: 196-221.

Stellenbosch University. Guidelines for dealing with the rape or sexual assault of students and staff of Stellenbosch University. https:/www.sun.ac.za/english/community-interaction-personnel/hiv/ Documents/Rape\%20-Sexual\%20Assault.pdf

University of Cape Town. Sexual harassment policy. http:/www.uct.ac.za/sites/default/files/ image_tool/images/328/about/policies/PolicySexual_Harassment_2008.pdf

University of Johannesburg. Sexual harassment policy. https://www.uj.ac.za/about/Documents/ policies/Sexual\%20Harassment\%20Policy.pdf

University of KwaZulu-Natal. Sexual harassment policy. http://chs.ukzn.ac.za/Files/finance/Sexual $\% 20$ Harassment $\% 20$ Policy.pdf

University of South Africa. Policy on academic integrity. http:/www.unisa.ac.za/static/ intranet/Content/Departments/College $\% 20$ of $\% 20$ Graduate $\% 20$ Studies/Documents/Policy\%20on \%20Academic\%20Integrity\%20-\%20appr\%20-\%20Council\%20-\%2010.06.2017.pdf

University of the Western Cape. Sexual harassment policy. https://www.uwc.ac.za/ $\mathrm{SO} / \mathrm{HR} /$ Pages/policies.aspx

University of the Witwatersrand. Sexual harassment, sexual assault and rape policy and procedures. https://www.wits.ac.za/media/wits-university/students/gender-equity-and-tolerance/documents/ HRG.10\%207\%20Apr\%202014\%20Wits\%20Sexual\%20Harassment\%20Policy.pdf

University of the Witwatersrand. Policy on sexual and romantic relationships between staff and undergraduate and honours students. https://www.wits.ac.za/media/wits-university/ students/gender-equity-and-tolerance/documents/Document $\% 2020 \% 20 \% 20$ Policy\%20on\%20 Sexual\%20and\%20Romantic\%20Relationships.pdf

Van Wyk, Anim. 2014. How many professors are there in South Africa? Africa Check, August 18, 2014. https://africacheck.org/reports/how-many-professors-are-there-in-sa/

White House Council on Women and Girls Rape and Sexual Assault. 2014. A renewed call to action. Washington: White House Council on Women and Girls, Office of the Vice President. https://obamawhitehouse.archives.gov/blog/2014/01/22/renewed-call-action-end-rape-andsexual-assault

Wilkinson, Kate. 2016. Guide: Rape statistics in South Africa. Africa Check June 22, 2016. https://africacheck.org/factsheets/guide-rape-statistics-in-south-africa/

Woolman, Stu and Matthew Chaskalson. 2009. Constitutional Law of South Africa vol. 3. Cape Town: 
Juta.

Young, Sherry. 1996. Getting to yes: The case against banning consensual relationships in higher education. The American Journal of Gender and the Law 4(269): 1-35.

Zwane, Thuletho. 2013. Wits staff in sex harassment inquiry. Wits Vuvuzela April 13, 2013. http://witsvuvuzela.com/2013/04/13/wits-staff-in-sex-harassment-inquiry/ 